\title{
O EFEITO DA REGULAÇÃO TRABALHISTA E T'RIBUTÁRIA NOS INVESTIMENTOS NO BRASIL
}

REINATA CARDOSO FERRETTI

Mestre em Administração pelo Programa de Pós-Graduação em Administração da Universidade Fundação Instituto Capixaba de Pesquisas em Contabilidade,

Economia e Finanças Business School (Fucape). Pesquisadora do Centro de Pesquisa em Finanças da Universidade Fundação Instituto Capixaba de

Pesquisas em Contabilidade, Economia e Finanças Business School (Fucape). Avenida Fernando Ferrari, 1.358, Boa Vista, Vitória - ES - Brasil - CEP 29075-505

E-mail: referretti@yahoo.com.br

BRUNO FUNCHAL

Doutor em Economia pela Escola de Pós-Graduação em Economia da

Fundação Getulio Vargas do Rio de Janeiro (FGV-RJ). Professor do Programa de Pós-Graduação da Universidade Fundação Instituto Capixaba de

Pesquisas em Contabilidade, Economia e Finanças Business School (Fucape). Avenida Fernando Ferrari, 1.358, Boa Vista, Vitória - ES - Brasil - CEP 29075-505

E-mail: bfunchal@fucape.br 


\section{RESUMO}

O objetivo deste estudo é avaliar o efeito da regulação trabalhista e tributária no investimento interno (formação bruta de capital fixo) e externo (fluxo de entrada de investimento estrangeiro direto). Assim, buscou-se fornecer evidências empíricas dos efeitos da legislação trabalhista e tributária sobre os investimentos e as estratégias de negócios no Brasil. Estudos nesse campo se justificam pelo fato de a regulação ter impacto substancial na atividade econômica dos agentes, porque, apesar de razões econômicas, sociais e políticas serem usadas para justificar a regulação, raramente alguma evidência empírica é utilizada como base ou justificativa para regulação (ALMEIDA; CARNEIRO, 2005). O foco no Brasil é relevante por ser um dos países mais regulados do mundo no âmbito trabalhista e tributário, apresentando baixo enforcement (BOTERO et al., 2004), já que a rigidez dessas legislações pode ser um fator interferente no baixo desempenho e investimentos das empresas e no crescimento econômico do país. Para investigar o efeito da regulação trabalhista e tributária no investimento interno e externo, foram aplicados testes por meio do método de Regressão Quantílica (RQ). Para efeito de análise comparativa, os testes foram rodados também pelo método dos Mínimos Quadrados Ordinários (MQO). O estudo é cross-country baseado em dados em pooled cross-section de I80 países, coletados no período de 2003 a 2006 para regulação trabalhista e no período de 2005 a 2006 para regulação tributária. Os dados relativos às variáveis de investimentos interno e externo (variáveis dependentes), bem como do PIB, população total e taxa de juros (variáveis de controle), são provenientes do World Development Indicators atualizado no ano de 2008 . Os resultados encontrados sugerem que quanto maior a rigidez da regulação do trabalho, menor o nível de investimento em termos de formação bruta de capital fixo e investimento estrangeiro direto no Brasil. Quanto ao efeito da regulação tributária sobre os investimentos, os resultados demonstram que há significância estatística e que uma redução da carga tributária, medida pela tributação sobre o lucro empresarial, pode elevar os níveis de investimentos. 


\section{PALAVRAS-CHAVE}

Regulação trabalhista e tributária; Investimentos no Brasil; Banco Mundial; PIB; Desempenho econômico.

\section{INTRODUÇÃO}

O objetivo deste estudo é analisar o efeito da regulação trabalhista e tributária no investimento interno (formação bruta de capital fixo) e externo (fluxo de entrada de investimento estrangeiro direto), buscando fornecer evidências empíricas dos efeitos dessas legislações sobre os investimentos e as estratégias de negócios no Brasil. A regulação da economia por parte do Estado é pano de fundo de estudos em diferentes áreas do conhecimento (ALMEIDA; CARNEIRO, 2005; DJANKOV et al., 2008). No campo da economia, a existência de falhas de mercado justifica a necessidade de regulação na tentativa de estabelecer ganhos de bem-estar para os agentes econômicos. A regulação, contudo, pode gerar custos no ambiente econômico e social, e a estrutura das legislações e das instituições pode ter efeitos adversos que muitas vezes vão de encontro à finalidade e ao objeto de tutela estatal.

Economistas, em geral, estudam o impacto das instituições sobre os resultados econômicos e sociais (ALMEIDA; CARNEIRO, 2005). Os resultados desses estudos evidenciam os efeitos adversos da regulação que importam não apenas para a avaliação e o desenho de legislações e políticas públicas (DJANKOV et al., 2008), mas também para pensar sobre o desempenho econômico das empresas e dos países. No âmbito da regulação trabalhista e tributária, tendo em vista os grandes impactos sobre os custos e sobre os resultados das empresas, a discussão a respeito dos efeitos adversos das legislações dessa natureza vem sendo objeto de estudos em diversos países, ainda que no Brasil a literatura seja incipiente nessa área.

Almeida e Carneiro (2005) estudaram o mercado de trabalho no Brasil e constataram que, em Estados onde o enforcement ${ }^{1}$ da lei trabalhista é mais rigoroso, as empresas empregam menor quantidade de emprego informal, porém, ao mesmo tempo, decresce a média dos salários, a produtividade e os investimentos. Verificam-se uma diminuição no valor adicionado por trabalhador, vendas por trabalhador, salários líquidos por trabalhador e investimento em tecnologia.

Fazer valer a lei. 
Ainda com relação à regulação do trabalho, Botero et al. (2004) examinaram o complexo de leis trabalhistas em 85 países e concluíram que legislações trabalhistas rigorosas têm consequências adversas no desemprego. Djankov et al. (2008), por sua vez, em uma análise com uma amostra de 85 países sobre os efeitos dos tributos incidentes sobre as empresas no investimento e no empreendedorismo, encontraram que uma elevada carga de tributos incidentes sobre a empresa está associada à grande economia informal e ao baixo crescimento econômico, com impactos adversos no investimento agregado, no investimento externo e na atividade empreendedora.

Estudos nesse campo se justificam pelo fato de a regulação ter impacto substancial na atividade econômica dos agentes, como também porque, apesar de razões econômicas, sociais e políticas serem usadas para justificar a regulação, raramente alguma evidência empírica é utilizada como base ou justificativa para regulação (ALMEIDA; CARNEIRO, 2005). Nesse sentido, este estudo busca fornecer evidências empíricas do efeito da regulação trabalhista e tributária sobre os investimentos no Brasil, contribuindo com argumentos empíricos para discussão dos efeitos adversos das legislações e para eventuais reformas no âmbito regulatório trabalhista e tributário no país. O foco no Brasil é relevante por ser um dos países mais regulados do mundo no âmbito trabalhista e tributário apresentando baixo enforcement (BOTERO et al., 2004), já que a rigidez dessas legislações pode ser um fator interferente no baixo desempenho e investimentos das empresas e no crescimento econômico do país.

Assim, o escopo deste estudo é responder à seguinte questão: "Qual é o efeito da regulação trabalhista e tributária no investimento interno e externo no Brasil?" Objetiva-se, portanto, investigar qual é o efeito da regulação trabalhista (em termos de flexibilidade/rigidez da legislação) e tributária (em relação ao nível de carga tributária) no investimento interno (medido pela formação bruta de capital fixo) e externo (investimento estrangeiro direto) no Brasil. O interesse em analisar o efeito sobre os investimentos (interno e externo) se dá em razão de seu impacto sobre as estratégias de negócios e sobre o desempenho da economia.

Os resultados encontrados sugerem que quanto maior a rigidez da regulação do trabalho, menores os níveis de investimentos em termos de formação bruta de capital fixo e investimento estrangeiro direto no Brasil. A análise dos resultados dos testes relacionados ao efeito da regulação tributária no investimento interno demonstrou significância estatística, ou seja, foi encontrada relação entre a carga tributária incidente sobre as empresas, tomando com base a tributação total sobre o lucro empresarial, e os níveis de investimentos, considerando os índices de formação bruta de capital fixo e o fluxo de entrada de investimento estrangeiro direto (ambos em percentual sobre o PIB). 
Diante disso, o texto está estruturado da seguinte forma: além desta introdução, na seção 2 é exposta uma revisão teórica abordando a teoria da regulação e um panorama de estudos anteriores no campo da regulação trabalhista e tributária; na seção 3 é discutido o contexto brasileiro; na seção 4 é apresentada a metodologia; e na seção 5 são analisados os resultados empíricos encontrados. Ao final são apresentadas as conclusões do estudo.

\section{REGULAÇÃO}

\subsection{A REGULAÇÃO E A NOÇÃO DE EFICIÊNCIA}

No presente contexto, os países escolhem a combinação de intervenções no mercado que maximiza o bem-estar social. O propósito é corrigir as falhas de mercado, buscando o máximo de eficiência, ou seja, uma alocação de instituições e recursos que maximize valor (POSNER, 2003).

Demsetz (I967 apud DJANKOV et al., 2003) e North (I98I apud DJANKOV et al., 2003) propuseram que a escolha das instituições e intervenções no mercado é ditada primariamente por considerações de eficiência. A noção de eficiência sugere que as instituições (entendidas de formal genérica) se ajustam para servir as necessidades da sociedade mais eficientemente. Dessa forma, cada país escolhe um sistema de controle dos negócios que melhor combine forças de mercado, resolução de conflitos na Justiça, regulação governamental, tributos e subsídios corretivos (DJANKOV et al., 2003).

Para Botero et al. (2004), a eficiência na intervenção governamental no mercado de trabalho na forma de proteção ao trabalhador é maior, por exemplo, quando os benefícios da regulação para proteger trabalhadores são maiores do que os efeitos adversos gerados, como desemprego, crescimento da economia informal, entre outros. Nesse sentido, os governos dos vários países do mundo encontram o desafio de encontrar a balança certa entre proteção do trabalhador e flexibilidade do mercado. Em alguns casos, porém, especialmente em países em desenvolvimento, a regulação tende para um extremo, empurrando os empregadores e trabalhadores para a economia informal (DOING BUSINESS, 2009). Pesquisas mais recentes têm buscado identificar intervenções públicas que são, ao mesmo tempo, menos custosas e menos vulneráveis a subversão e, em geral, mais eficientes (GLAESER; SCHEINKMAN; SHLEIFER, 2002; DJANKOV et al., 2003).

A eficiência do sistema normativo não implica dizer a promoção da distribuição de riqueza por meio de modelos assistencialistas e legislações extremamente onerosas, pois, na maior parte das vezes, esses modelos vão de encontro 
à criação de riqueza, desenvolvimento e bem-estar geral. A eficiência está relacionada com a aptidão para alcançar a função prevista da forma mais produtiva, empregando os menores custos, reduzindo o desperdício de recursos e prevendo efeitos adversos na distribuição de renda e no bem-estar econômico (COOTER; ULEN, 2004).

\subsection{REGULAÇÃO TRABALHISTA E TRIBUTÁRIA E DESEMPENHO ECONÔMICO}

Um dos pontos de debate na literatura econômica é investigar de que forma o conjunto de leis e instituições dos países pode explicar diferenças em crescimento econômico, competitividade e desempenho de empresas, empreendedorismo, desigualdade social, desemprego etc. No que tange à regulação trabalhista e tributária, a relevância dessas discussões se torna ainda mais evidente, tendo em vista a influência de tais legislações sobre o desenvolvimento econômico dos países e a importância das relações tuteladas (relações de trabalho e tributária).

Em geral, estudos empíricos que abordam a regulação do trabalho buscam analisar os efeitos adversos das leis trabalhistas que, ao objetivarem tutelar os interesses dos trabalhadores nas relações de trabalho, acabam por gerar, em alguns casos, menor participação do trabalhador, salários menores, maior desemprego, entre outros. O debate gira em torno da premissa de que alguma forma de intervenção é claramente justificada pela necessidade de proteger trabalhadores de ações arbitrárias dos empregadores, a qual pode ser particularmente importante na ausência de redes de seguridade social efetivas. Ocorre que disposições de proteção ao trabalho onerosas podem aumentar os custos trabalhistas e, dessa forma, reduzir o investimento em qualificação dos empregados e a flexibilidade da empresa para lidar com a rapidez da mudança da economia global e aproveitar as oportunidades oferecidas pelas novas tecnologias e pelo acesso a novos mercados (PIERRE; SCARPETTA, 2005).

Análise entre economias mostra que, apesar de a regulação do trabalho em geral aumentar a estabilidade e os salários dos trabalhadores em exercício, regulamentações excessivamente rígidas podem ter efeitos colaterais indesejáveis, como criação de menos empregos, limitação no crescimento do porte da empresa, menor investimento em pesquisa e desenvolvimento, maior desemprego e, portanto, obsolescência das competências, o que pode reduzir o crescimento da produtividade (DOING BUSINESS, 2009).

Lazear (I990), em uma análise pioneira cross-country com uma amostra de 20 países, durante o período de 1956-1984, encontrou relação positiva entre a 
medida de proteção ao emprego e o desemprego (PIERRE; SCARPETTA, 2005). A partir daí, as metodologias dos estudos vêm sendo refinadas e ampliadas, o conceito de proteção ao emprego tem sido aprofundado, e há diferentes padrões de resultados para amostras de diferentes países.

Besley e Burgess (2002) demonstraram que estados da Índia com a legislação trabalhista pró-trabalhador experimentaram menores resultados, empregos, investimentos e produtividade. Ao mesmo tempo, o nível de produção não registrada e trabalho informal eram maiores, além de haver maiores níveis de pobreza urbana. Sob diferente abordagem, Pierre e Scarpetta (2005) identificaram que nem todas as empresas são afetadas da mesma forma pela onerosidade das leis de proteção ao trabalho. As empresas de médio porte e firmas inovadoras são aquelas em que o negócio e as perspectivas de crescimento são mais negativamente afetadas.

Javorcik e Spatareanu (2006), por sua vez, evidenciaram que a flexibilidade no mercado do trabalho do país que recebe o investimento, em termo absoluto ou relativo em relação à do país investidor, é associada à maior probabilidade de investimento e a maiores fluxos de investimento externo direto, especialmente investimentos provenientes de empresas do setor de serviços, que são mais sensíveis à regulação do mercado de trabalho.

Em relação à regulação tributária, objeto de estudo no campo das finanças públicas e desenvolvimento (DJANKOV et al., 2008), uma das questões essenciais de pesquisa é avaliar os efeitos do nível de carga tributária sobre o crescimento econômico dos países. Um dos desafios-chave do desenvolvimento econômico é identificar as políticas que prejudicam ou impedem o crescimento, juntamente com uma avaliação da sua eficácia na redução da pobreza (BESLEY; BURGESS, 2002).

Djankov et al. (2008) investigaram os efeitos dos tributos corporativos no investimento e no empreendedorismo. Eles constataram que elevada carga de tributos incidentes sobre as empresas está associada com uma grande atividade informal e com um baixo crescimento econômico, e tem impactos adversos no investimento agregado, no investimento externo e na atividade empreendedora. Segundo Davis e Henrekson (2004), uma alta carga tributária aumenta a economia informal, altera o mix da indústria, reduz o valor adicionado e amplifica os efeitos negativos do mercado de trabalho. Além disso, segundo os autores, existem evidências empíricas de que elevada carga tributária desencoraja o fluxo de investimento estrangeiro direto (IED), o que justifica o fato de muitos governos manterem a carga tributária baixa com intuito de encorajar o investimento.

Estudos empíricos sugerem ainda que, em geral, os países têm respondido de forma melhor à mobilidade internacional, reduzindo de forma relativa ou 
absoluta a tributação de investidores internacionais, embora continuem a tributar o investimento nacional com altas taxas (DESAI; HINES; J. FOLEY, 200I).

\section{O CONTEXTO BRASILEIRO}

\subsection{REGULAÇÃO TRABALHISTA E TRIBUTÁRIA}

A regulação do trabalho na maioria dos países é estabelecida por um sistema de leis e instituições que visam proteger os interesses dos trabalhadores e assegurar um padrão mínimo de direitos para proteção do emprego. Em geral, esse sistema engloba três corpos de leis: leis relacionadas ao contrato individual de trabalho, legislações das relações coletivas de trabalho e leis de seguridade social (BOTERO et al., 2004).

Apesar disso, a configuração da lei trabalhista varia de acordo com o ambiente regulatório dos países e outras determinantes, tais como origem legal, ambiente político, econômico e social, momento histórico, entre outros, não existindo um padrão nas leis e instituições reguladoras do trabalho dos países. Logo, os efeitos da regulação sobre atributos econômicos também podem variar de acordo com o contexto do país. No Brasil, a Consolidação das Leis do Trabalho (CLT) ${ }^{2}$ é a principal norma jurídica responsável por tutelar as relações de trabalho e emprego. Evidências sugerem que a regulação trabalhista no Brasil caracteriza-se por uma alta rigidez (ou seja, pouca flexibilidade) das legislações e vagarosidade das instituições correlatas responsáveis pela operacionalização dessas legislações.

Segundo dados do Doing Business (2009), o Brasil figura como um país com grande rigidez na proteção ao trabalho, na $28^{a}$ posição entre I 80 países, considerando o índice médio RegTrab, que mede dificuldade de contratação, a rigidez das horas de trabalho, a dificuldade de demissão e a rigidez total do emprego, mensurado em uma escala de o a Io० (valores maiores indicam maior rigidez). Ainda, considerando os custos de demitir medidos em salários por semana (em dólares, segundo a metodologia do Doing Business (2009)3), o Brasil é o $75^{\circ}$ entre I8o países. Assim, em linhas gerais, o Brasil tende para uma maior rigidez do que flexibilidade da regulação trabalhista, conforme se observa nos índices demonstrados na Tabela I. 


\section{TABELA I}

REGULAÇÃO TRABALHISTA - REGIÖES/ECONOMIA E BRASIL

Índice de rigidez ou flexibilidade da regulação trabalhista.

Valores maiores indicam maior rigidez.

Dados referentes a 180 países.

\begin{tabular}{lcc}
\hline REGIÃO OU ECONOMIA & $\begin{array}{c}\text { REGTRAB } \\
\text { (ESCALA 0-100) }\end{array}$ & $\begin{array}{c}\text { CUSTOS DE DEMISSÃO } \\
\text { (SALÁRIOS POR SEMANA) }\end{array}$ \\
\hline Leste Asiático e Pacífico & 15,8 & 42,4 \\
\hline Europa Oriental e Ásia Central & 29,22 & 27,8 \\
\hline América Latina e Caribe & 26,6 & 53,0 \\
\hline Oriente Médio e África do Norte & 24,47 & 53,4 \\
\hline OECD & 26,4 & 26,6 \\
\hline Sul da Ásia & 26,35 & 75,8 \\
\hline África Subsaariana & 35,47 & 67,6 \\
\hline Brasil & 46 & 48 \\
\hline
\end{tabular}

*RegTrab: média de quatro índices que mensuram: dificuldade de contratação, rigidez de horas de trabalho, dificuldade de demissão e rigidez total de emprego, medidos em uma escala de o a ı००.

Fonte: Doing Business (2009).

Em relação à carga tributária, pode-se dizer que ela é definida pela quantidade de tributos (impostos, taxas e contribuições) das três esferas de governo (federal, estadual e municipal) incidentes sobre a economia, que é formada pelos indivíduos, pelas empresas e pelos governos nos seus três níveis (AMARAL et al., 2009).

Países desenvolvidos, em geral, têm uma estrutura tributária mais eficiente, com uma menor quantidade de tributos, quando comparados com países menos desenvolvidos. Isso não implica dizer que necessariamente eles cobram menos impostos em termos porcentuais do Produto Interno Bruto (PIB), mas que possuem uma estrutura de leis, instituições e incentivos às pessoas e às empresas que opera de forma mais eficiente na arrecadação dos impostos (AMARAL et al., 2009).

O sistema tributário brasileiro é composto por 6r tributos federais, estaduais e municipais. Em 2007, a carga tributária correspondeu a 35,3\% do PIB (AMARAL et al., 2009). Segundo dados do Doing Business (2009), o Brasil aparece na $157^{a}$ posição entre I8o países em relação ao número de pagamentos por ano, evidenciando um número de pagamentos de impostos por ano relativamente 
menor que a maioria dos países da amostra deste estudo. Quanto ao índice total de tributação sobre o lucro empresarial, o Brasil encontra-se no i $8^{\circ}$ lugar, o que evidencia uma tributação comparativamente maior sobre o lucro empresarial do que os demais países da amostra.

Ainda, quanto ao tempo necessário para preparo e pagamento de impostos, o Brasil aparece em I ${ }^{\circ}$ lugar entre i8o países, evidenciando a morosidade do sistema e das instituições relacionadas à arrecadação de impostos no Brasil, conforme se observa nas tabelas 2 e 3 .

\section{TABELA 2}

\section{REGULAÇÃO TRIBUTÁRIA - TEMPO}

\begin{tabular}{lccc}
$\begin{array}{l}\text { Índice relacionado ao tempo gasto para preparo e pagamento de impostos por ano. } \\
\text { Valores expressos em horas por ano. Dados referentes a } 180 \text { países. }\end{array}$ \\
$\begin{array}{l}\text { MAIOR RAPIDEZ } \\
\text { (MENOR TEMPO) }\end{array}$ & $\begin{array}{c}\text { TEMPO } \\
\text { (HORAS POR ANO) }\end{array}$ & $\begin{array}{c}\text { MAIOR MOROSIDADE } \\
\text { (MAIOR TEMPO) }\end{array}$ & $\begin{array}{c}\text { TEMPO } \\
\text { (HORAS POR ANO) }\end{array}$ \\
\hline Maldivas & 0 & Ucrânia & 848 \\
\hline Emirados Árabes & 12 & Venezuela & 864 \\
\hline Bahrein & 36 & República Checa & 930 \\
\hline Catar & 36 & Nigéria & 938 \\
\hline Bahamas & 58 & Armênia & 958 \\
\hline Luxemburgo & 59 & Vietnã & 1.050 \\
\hline Santa Lúcia & 61 & Bolívia & 1.080 \\
\hline Omã & 62 & Bielorrússia & 1.188 \\
\hline Suíça & 63 & Camarões & 1.400 \\
\hline Nova Zelândia & 70 & Brasil & 2.600 \\
\hline
\end{tabular}

Fonte: Doing Business (2009).

Destaca-se que, considerando o tempo em horas por ano, uma empresa na média no Brasil demora 2.600 horas para preparo e pagamento de impostos diretos e indiretos, tempo muito superior à média das demais regiões e economias.

A Tabela 3 demonstra que no Brasil, em termos de número de pagamentos, na média, as empresas brasileiras pagam ro impostos por ano, enquanto empresas da Europa Oriental e Ásia Central, por exemplo, pagam aproximadamente 46 impostos, e empresas da América Latina e Caribe, 33 impostos. Contudo, embora o número de impostos seja inferior no Brasil, o percentual sobre o lucro 
que esses impostos representam no país é de $69,2 \%$, bem superior ao das regiões citadas, que registram índices de 43,4\% (Europa Oriental e Ásia Central) e 48,3\% (América Latina).

\section{TABELA 3}

REGULAÇÃO TRIBUTÁRIA - REGIÕES/ECONOMIA E BRASIL

Índice relacionado à carga tributária. Valores maiores indicam maior rigidez.

Dados referentes a 180 países.

\begin{tabular}{lccc}
\hline REGIÃO OU ECONOMIA & $\begin{array}{c}\text { NÚMEROS DE } \\
\text { PAGAMENTOS POR ANO }\end{array}$ & $\begin{array}{c}\text { TEMPO } \\
\text { (HORAS POR ANO) }\end{array}$ & $\begin{array}{c}\text { IMPOSTO TOTAL SOBRE } \\
\text { O LUCRO (\% LUCRO) }\end{array}$ \\
\hline Leste Asiático e Pacífico & 24,6 & 227,1 & 36,8 \\
\hline $\begin{array}{l}\text { Europa Oriental e Ásia } \\
\text { Central }\end{array}$ & 46,3 & 336,3 & 43,4 \\
\hline América Latina e Caribe & 33,2 & 385,2 & 48,3 \\
\hline $\begin{array}{l}\text { Oriente Médio e África do } \\
\text { Norte }\end{array}$ & 22,9 & 204,2 & 32,9 \\
\hline OECD & 12,8 & 194,1 & 44,5 \\
\hline Sul da Ásia & 31,3 & 284,5 & 40,0 \\
\hline África Subsaariana & 37,7 & 306,0 & 67,5 \\
\hline Brasil & 10 & 2,600 & 69,2 \\
\hline
\end{tabular}

Fonte: Doing Business (2009).

Em geral, os países diferem-se não apenas em termos de regulação trabalhista e tributária, mas também quanto a políticas comerciais e regulatórias, características de seus mercados de trabalho, natureza da competição no mercado de produtos, custo e disponibilidade local de suprimentos, proximidade de mercados finais (HINES, 2005) e outras circunstâncias políticas, econômicas e culturais. O fato é que esses atributos em conjunto ou isoladamente podem influenciar a conveniência de se investir em determinado país, aumentando ou diminuindo o fluxo de investimento direto atraído, e, ainda, determinar o montante investido pelas empresas em suas operações internas.

\subsection{INVESTIMENTO INTERNO E EXTERNO}

Existem vários tipos e fontes de investimentos que operam no ambiente econômico de atuação das empresas. No âmbito do presente estudo, o objetivo foi 
focar o "investimento interno" como aquele proveniente de dentro do país e direcionado para dentro da empresa, medido em termos de formação bruta de capital fixo (FBCF), e o "investimento externo", aquele proveniente de fora do país e determinado pelo fluxo de entrada de investimento estrangeiro direto (IED).

$\mathrm{O}$ investimento interno medido pela formação bruta de capital fixo (FBCF) é o valor total das aquisições ou melhorias em ativos fixos (bens factíveis de utilização repetida e contínua em outros processos produtivos sem serem efetivamente consumidos por eles) durante o período contábil. Esse investimento é importante porque indica o crescimento da capacidade produtiva e a confiabilidade dos empresários no país (INSTITUTO BRASILEIRO DE GEOGRAFIA E ESTATÍSTICA, 2009; INSTITUTO DE PESQUISA ECONÔMICA APLICADA, 2009; ORGANISATION FOR ECONOMIC CO-OPERATION AND DEVELOPMENT, 2009).

Já o investimento estrangeiro direto (IED) é capital investido com o intuito de obter um interesse duradouro em uma empresa que opera em outra economia diferente da do investidor. O interesse duradouro implica a existência de uma relação de longo prazo entre o investidor direto e a empresa, assim como um grau significativo de influência no uso da empresa. O investimento estrangeiro direto funciona como principal direcionador da globalização dos mercados entre países e uma importante fonte de capital e desenvolvimento econômico (ORGANISATION FOR ECONOMIC CO-OPERATION AND DEVELOPMENT, 2009; WORLD DEVELOPMENT INDICATORS, 2008; UNITED NATIONS CONFERENCE ON TRADE AND DEVELOPMENT, 2009).

Segundo base de dados World Development Indicators (2008), do Banco Mundial atualizada em 2008, o Brasil durante os anos de 2000 a 2006 apresentou um índice de formação bruta de capital fixo (\% PIB) abaixo da média de outras regiões/países. Os níveis de investimento estrangeiro direto (\% PIB) apresentam variações para o mesmo período de análise, conforme se verifica nas tabelas 4 e 5 .

TABELA 4

FORMAÇÃO BRUTA DE CAPITAL FIXO - REGIÕES E BRASIL

Índice de formação bruta de capital fixo - \% PIB.

Dados referentes aos anos de 2000-2006.

FORMAÇÃO BRUTA DE CAPITAL FIXO $(\% \mathrm{PIB})$

$\begin{array}{lllllll}2000 & 2001 & 2002 & 2003 & 2004 & 2005 & 2006\end{array}$ MÉDIA

Europa e Ásia Central

$\begin{array}{llllllll}20,69 & 20,09 & 19,05 & 19,04 & 19,79 & 20,27 & 21,14 & 20,01\end{array}$

Leste Asiático e Pacífico

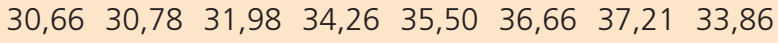

(continua) 


\section{TABELA 4 (CONCLUSÃO)}

\section{FORMAÇÃO BRUTA DE CAPITAL FIXO - REGIÕES E BRASIL}

\begin{tabular}{llllllllll}
\hline $\begin{array}{l}\text { FORMAÇÃO BRUTA DE CAPITAL FIXO } \\
\text { (\% PIB) }\end{array}$ & 2000 & 2001 & 2002 & 2003 & 2004 & 2005 & 2006 & MÉDIA \\
\hline América Latina e Caribe & 18,43 & 18,02 & 17,14 & 16,84 & 18,14 & 18,72 & 19,76 & 18,15 \\
\hline Oriente Médio e África do Norte & 21,52 & 21,72 & 22,21 & 22,78 & 23,23 & 23,07 &.. & 22,42 \\
\hline Sul da Ásia & 22,18 & 22,22 & 22,76 & 23,64 & 24,89 & 26,51 & 27,98 & 24,31 \\
\hline Brasil & 16,80 & 17,03 & 16,39 & 15,28 & 16,10 & 16,27 & 16,80 & 16,38 \\
\hline
\end{tabular}

Fonte: World Development Indicators (2008).

Observa-se que, no período de 2000 a 2006 , não houve muita variação, em termos de percentual sobre o PIB, do volume de capital investido em ativos fixos no Brasil, considerando o índice de formação bruta de capital fixo. Por sua vez, o volume de investimento estrangeiro direto em percentual sobre o PIB teve grande variância durante o mesmo período no Brasil, registrando um índice de 50,86\% em 2000, I8,36\% em 2003 e I7,59\% em 2006.

\section{TABELA 5}

\section{INVESTIMENTO ESTRANGEIRO DIRETO - REGIÕES E BRASIL}

\begin{tabular}{|c|c|c|c|c|c|c|c|c|}
\hline $\begin{array}{l}\text { INVESTIMENTO ESTRANGEIRO DIRETO } \\
(\% \mathrm{PIB})\end{array}$ & 2000 & 2001 & 2002 & 2003 & 2004 & 2005 & 2006 & MÉDIA \\
\hline Europa e Ásia Central & 27,58 & 28,35 & 24,4 & 26,45 & 37,69 & 34,8 & 49,89 & 32,74 \\
\hline Leste Asiático e Pacífico & 26,47 & 26,98 & 29,67 & 25,04 & 26,69 & 34,46 & 29,33 & 28,38 \\
\hline América Latina e Caribe & 39,80 & 37,23 & 30,82 & 23,59 & 31,07 & 27,87 & 24,00 & 30,63 \\
\hline Oriente Médio e África do Norte & 12,47 & 10,39 & 12,25 & 18,36 & 13,99 & 24,76 & 42,42 & 19,23 \\
\hline Sul da Ásia & 72,23 & 98,54 & 10,29 & 70,57 & 86,27 & 98,80 & 20,13 & 65,26 \\
\hline Brasil & 50,86 & 40,66 & 32,79 & 18,36 & 27,36 & 17,21 & 17,59 & 29,26 \\
\hline
\end{tabular}

Fonte: World Development Indicators (2008). 
Segundo a Sociedade Brasileira de Estudos de Empresas Transnacionais e da Globalização Econômica (Sobeet) a partir de dados do Factbook 2008 (relatório anual divulgado pela Organização para Cooperação e Desenvolvimento EconômiCo - OCDE), o fluxo de investimentos estrangeiros diretos (IED) no Brasil aumentou $30,3 \%$ em 2008 , na comparação com 2007 , para US $\$ 45$, I bilhões. Na proporção entre investimento estrangeiro direto (IED) realizado e Produto Interno Bruto (PIB) de cada país, o Brasil apresenta uma relação de $18,3 \%$, melhor situação entre os Brics ${ }^{4}$. A Rússia recebeu a título de investimentos o equivalente a I2,7\% do seu produto interno em 2008. Os investimentos na Índia corresponderam à proporção de 9,9\% e na China 8,7\% do PIB. Ainda, segundo dados da United Nations Conference on Trade and Development - Unctad (2009), a média de investimento estrangeiro no mundo em relação ao PIB global é de $26,9 \%$.

Apesar disso, enquanto o IED aumentou $30,3 \%$ de 2007 para 2008 no Brasil, o investimento de empresas nacionais na formação bruta de capital fixo (FBCF) ${ }^{5}$ cresceu 13,8\%. Dessa forma, o aumento do investimento estrangeiro direto (IED) em 2008 superou o crescimento dos investimentos das empresas nacionais no país em termos de formação bruta de capital fixo, ao contrário do que ocorreu no restante do mundo (OCDE, 2009).

\section{METODOLOGIA}

\subsection{REGRESSÃO QUANTÍLICA}

Para investigar o efeito da regulação trabalhista e tributária no investimento interno e externo, foram aplicados testes por meio do método de regressão quantílica (RQ). Para efeito de análise comparativa, os testes foram rodados também pelo método dos mínimos quadrados ordinários (MQO).

A análise estatística baseada na regressão quantílica permite visualizar a associação da variável independente com as variáveis dependentes em seus diversos quantis da distribuição condicional.

O quantil de distribuição no modelo de regressão quantílica é a nomenclatura geral de uma segmentação da população. Assim, enquanto os quartis dividem a população em quatro segmentos com igual proporção, os quintis dividem a população dentro de cinco partes e os decis em dez partes, os quantis ou percentis são a nomenclatura geral (HALLOCK; KOENKER, 2000).

4 Bric é a sigla para designar os quatro principais países emergentes do mundo, a saber: Brasil, Rússia, Índia e China.

5 Os investimentos em máquinas e equipamentos são os principais responsáveis pela formação bruta de capital fixo (FBCF) no país. 
A regressão quantílica pode ser vista como uma extensão do modelo clássico dos mínimos quadrados ordinários. Na metodologia de regressão dos mínimos quadrados, a função média condicional é quase tudo o que se pode conhecer da relação entre x e y (HALLOCK; KOENKER, 2000). Contudo, o efeito da média não é capaz de capturar os diversos níveis de sensibilidade da variável dependente para estratos diferentes da amostra, dificultando, por exemplo, a análise da situação de países em pontos extremos da amostra ou análise específica de algum país.

A regressão quantílica possibilita identificar os quantis representativos de países ou regiões ou de determinados países e, dessa forma, permite uma análise mais específica de certo país ou grupo de países.

Em conjunto, o grupo de funções quantílicas estimadas oferece uma visão mais completa dos efeitos em termos de localização, escala e forma de distribuição (HALLOCK; KOENKER, 2000). Como essa técnica permite investigar como cada quantil de interesse responde em vez de ter somente uma reta de regressão baseada na média, é possível obter uma análise mais específica do efeito da regulação trabalhista e tributária no investimento interno e externo no Brasil (de forma isolada) e em diversos estratos da amostra de países comparativamente.

\subsection{DADOS}

O estudo é cross-country baseado em dados em pooled cross-section de I8o países, coletados no período de 2003 a 2006 para regulação trabalhista e no período de 2005 a 2006 para regulação tributária.

Os dados relacionados à regulação trabalhista e regulação tributária (variáveis independentes) foram obtidos na base de dados do projeto Doing Business (2009). Os dados relativos às variáveis investimentos interno e externo (variáveis dependentes), bem como do PIB, da população total e da taxa de juros (variáveis de controle), são provenientes do World Development Indicators (2008).

A variável independente "regulação trabalhista" refere-se à rigidez ou flexibilidade da regulação trabalhista. A metodologia de coleta dos dados foi desenvolvida por Botero et al. (2004) e adequada pelo Doing Business (2009). Os índices que mensuram a regulação trabalhista são: I. índice de dificuldade de contratação: duração máxima dos contratos de prazo determinado e o salário mínimo para trabalhador sem experiência; 2. índice de rigidez das horas de trabalho: programação das horas extras e férias remuneradas; 3. índice de dificuldade de demissão: notificação e requisitos para rescisão do contrato de trabalho de um trabalhador ou grupo de trabalhadores, obrigação de recontratar e exigências legais relacionadas à demissão; 4. índice de rigidez do emprego: média simples desses três índices; 5 . custos de demitir: exigências de notificação, pagamentos de indenizações e outras penalidades relativas à demissão sem justa causa. 
- RAM, REV. ADM. MACKENZIE, V. 12, N. $4^{\bullet}$

Os quatro primeiros índices da regulação trabalhista são medidos em uma escala de o a Iо०, já o custo de demitir é expresso em número de semanas de salários em dólares (conversão da moeda do país em dólares pela metodologia do Doing Business (2009)).

Para a realização dos testes estatísticos no presente estudo, foi feita uma média dos quatro índices explicativos da regulação trabalhista mensurados na mesma escala (dificuldade de contratação, rigidez das horas de trabalho, dificuldade de demissão e rigidez do emprego), criando uma única variável representativa nomeada de "RegTrab". A variável explicativa "custo de demitir" não foi incluída no cálculo da variável RegTrab, pois é expressa em semanas de salário diferente das demais, mas foi utilizada na regressão junto à variável RegTrab. Assim, a variável independente regulação trabalhista foi desdobrada em duas variáveis independentes explicativas: RegTrab e custos de demissão.

Já a variável independente regulação tributária foi representada pela variável independente explicativa que mede a tributação total sobre o lucro (percentual sobre o lucro), isto é, o montante de impostos sobre os lucros pagos pela empresa.

A "regulação tributária" refere-se ao nível de carga tributária incidente sobre as empresas. Os dados são provenientes do Doing Business (2009) e demonstram os impostos e as contribuições obrigatórios que uma empresa de médio porte tem de pagar ou reter em um determinado ano. A metodologia de coleta desses dados foi desenvolvida por Djankov et al. (2008) e adaptada pelo Doing Business (2009).

A variável dependente "investimento interno" é medida pela formação bruta de capital fixo (percentual sobre o PIB), cuja fonte é a base de dados World Development Indicators (2008). A formação bruta de capital fixo (FBCF) é o valor total das aquisições ou melhorias em ativos fixos durante o período contábil. Esse indicador mede, portanto, o quanto as empresas aumentaram os seus bens de capital, por exemplo, máquinas, equipamentos, material de construção, entre outros (INSTITUTO BRASILEIRO DE GEOGRAFIA E ESTATÍSTICA, 2009; INSTITUTO DE PESQUISA ECONÔMICA APLICADA, 2009; ORGANISATION FOR ECONOMIC CO-OPERATION AND DEVELOPMENT, 2009).

Por fim, para variável dependente "investimento externo", são utilizados dados relativos ao fluxo de entrada de investimento estrangeiro direto (foreign direct investment - FDI, net inflows medido em percentual sobre o PIB), provenientes também da base de dados World Development Indicators (2008). O investimento estrangeiro direto é o capital investido com o propósito de aquisição de um interesse durável em uma empresa ou de exercício de um grau de influência nas operações dessa empresa que opera em outra economia diferente da do investidor (ORGANISATION FOR ECONOMIC CO-OPERATION AND DEVELOPMENT, 2009; WORLD DEVELOPMENT INDICATORS, 2008).

Além disso, foram utilizadas variáveis controles a fim de controlar outros impactos não decorrentes da regulação trabalhista e tributária e características 
de cada país da amostra que podem ter efeito no investimento interno e externo, quais sejam: população total, spread e PIB per capita, PPP (constant 2005, international \$), convertido pelo método Atlas World Bank - World Development Indicators. Para os testes relacionados à regulação tributária, o coeficiente da variável controle spread não foi significativo para os primeiros testes rodados, por esse motivo, optou-se por não utilizar essa variável como controle nos resultados dos testes que medeiam o efeito da regulação tributária nos investimentos interno e externo a fim de não perder graus de liberdade.

Além dessas variáveis, foram estabelecidas dummies relativas aos anos de 2003, 2004, 2005, 2006 para controlar os efeitos comuns a todos os países que evoluíram ao longo do tempo nos testes que tinham a regulação trabalhista como variável independente. Foi assumido o valor o ou i para cada ano, de modo que, por exemplo, a dummie do ano 2003 assumia o valor I para o ano de 2003 e o para os demais anos, sendo procedido do mesmo modo para as dummies relativas aos anos de 2004 e 2005. Destaca-se que essas dummies só foram utilizadas nos testes que buscavam avaliar a correlação entre a variável independente regulação trabalhista e as variáveis dependentes investimento interno e externo. Para regulação tributária, não foram utilizadas tais dummies, tendo em vista que, nesse caso, o período abrangido foi apenas os anos de 2005 e 2006 com número menor de observações.

A relação entre as variáveis foi estimada com base nas seguintes equações:

(I) $\mathrm{Y}_{i t}=\alpha+\beta_{\mathrm{I}}$ regtrab $_{i t}+\beta_{2}$ custodemissão $_{i t}+\theta X_{i t}+\varepsilon_{i t}$, por quartil

Onde:

Yi: investimento interno/formação bruta de capital fixo;

Yi: investimento externo/IED;

$\mathrm{Xi}$ : vetor de controle (PIB, população total e spread).

Variáveis independentes de interesse:

RegTrab;

Custos de demissão.

(2) $\mathrm{Y} i=\alpha+\beta_{\mathrm{I}}$ impostlucroempresarial $+\theta X i+\varepsilon i$, por quartil

Onde:

Yi: investimento interno/formação bruta de capital fixo;

Yi: investimento externo/IED;

$\mathrm{Xi}$ : vetor de controle (PIB, população total).

Variáveis independentes de interesse:

Imposto sobre lucro empresarial. 
O estudo buscou entender essa relação com foco no Brasil e de forma comparativa com outros países, motivo pelo qual foram rodados testes para outros quantis (0,I, ०,2, ०,3, ०,4, ०,5, ०,6, ०,7, ०,8 e ०,9), além dos quantis representativos do Brasil ( 0,54 nos testes relacionados ao impacto no investimento interno e 0,39 nos relacionados ao investimento externo).

Os quantis representativos do Brasil foram identificados da seguinte forma: para cada ano 2003, 2004, 2005 e 2006, foi feita uma classificação crescente da posição do Brasil em relação aos I8o países com dados de formação bruta de capital fixo (investimento interno) e fluxo de entrada de investimento estrangeiro direto (investimento externo). Após isso, foi dividida a posição do Brasil em cada ano pelo número total de países (I80 países), e, ao final, fez uma média simples dos resultados dessa divisão (posição do Brasil/número total de países) dos quatro anos de análise, obtendo-se o quantil representativo do Brasil para investimento interno e externo. O mesmo procedimento metodológico foi usado para a definição dos quantis de outros países utilizados na análise comparativa e exemplificação.

A análise de resultados se dá a partir dos testes rodados consolidados nas tabelas $6,7,8,9$, sendo duas relativas ao efeito da regulação trabalhista nos investimentos e outras duas relacionadas à relação entre a regulação tributária e os investimentos, além dos gráficos descritivos das variáveis independentes explicativas.

\section{RESULTAdOS}

\subsection{ANÁLISE DO EFEITO DA REGULAÇÃO TRABALHISTA E TRIBUTÁRIA NOS INVESTIMENTOS}

\subsubsection{Regulação trabalhista}

A Tabela 6 mostra as estimativas obtidas pela regressão quantílica (RQ) para os quantis o,I, ०,2, ०,3, ०,4, ०,5, ०,6, ०,7, ०,8, ०,9 e ०,54 (Brasil). Busca-se analisar o efeito da regulação trabalhista no investimento interno, portanto a variável dependente é o investimento interno (formação bruta de capital fixo), e a variável independente, a regulação trabalhista (RegTrab e custo de demitir). 


\section{TABELA 6}

\section{RESULTADOS POR RQ E MQO. EFEITO DA REGULAÇÃO TRABALHISTA NO INVESTIMENTO INTERNO}

\begin{tabular}{|c|c|c|c|c|c|c|c|c|c|c|c|}
\hline VARIÁVEL & MQO & $\mathrm{RQ} 0,1$ & $\mathrm{RQ} 0,2$ & $\mathrm{RQ} 0,3$ & $\mathrm{RQ} 0,4$ & $\mathrm{RQ} 0,5$ & $\mathrm{RQ} 0,6$ & RQ 0,7 & $\mathrm{RQ} 0,8$ & $\mathrm{RQ} 0,9$ & $\begin{array}{c}\text { RQ } \\
0,54 \\
\text { (BRASIL) }\end{array}$ \\
\hline RegTrab & $\begin{array}{c}-0,07^{* * *} \\
(0,002)\end{array}$ & $\begin{array}{c}-0,09 * * * \\
(0,000)\end{array}$ & $\begin{array}{c}-0,04^{* *} \\
(0,016)\end{array}$ & $\begin{array}{c}-0,05^{\star \star *} \\
(0,001)\end{array}$ & $\begin{array}{c}-0,06^{* * *} \\
(0,000)\end{array}$ & $\begin{array}{c}-0,07^{* * *} \\
(0,000)\end{array}$ & $\begin{array}{c}-0,07^{* * *} \\
(0,001)\end{array}$ & $\begin{array}{c}-0,05^{\star *} \\
(0,029)\end{array}$ & $\begin{array}{c}-0,07^{\star *} \\
(0,029)\end{array}$ & $\begin{array}{l}-0,06 \\
(0,505)\end{array}$ & $\begin{array}{c}-0,068^{* * *} \\
(0,001)\end{array}$ \\
\hline $\begin{array}{l}\text { Custo } \\
\text { de } \\
\text { demitir }\end{array}$ & $\begin{array}{l}-0,01 * \\
(0,054)\end{array}$ & $\begin{array}{l}-0,01 * \\
(0,081)\end{array}$ & $\begin{array}{l}-0,01^{*} \\
(0,066)\end{array}$ & $\begin{array}{c}-0,01 * * \\
(0,014)\end{array}$ & $\begin{array}{c}-0,01 \\
(0,108)\end{array}$ & $\begin{array}{c}-0,01 * * \\
(0,013)\end{array}$ & $\begin{array}{c}-0,02^{* * *} \\
(0,009)\end{array}$ & $\begin{array}{c}-0,02^{* * *} \\
(0,004)\end{array}$ & $\begin{array}{c}-0,03^{* * *} \\
(0,006)\end{array}$ & $\begin{array}{c}-0,02 \\
(0,331)\end{array}$ & $\begin{array}{c}-0,020 * * \\
(0,017)\end{array}$ \\
\hline PopTotal & $\begin{array}{c}0,00 * * * \\
(0,001)\end{array}$ & $\begin{array}{c}0,00 * * * \\
(0,000)\end{array}$ & $\begin{array}{c}0,00^{* * *} \\
(0,000)\end{array}$ & $\begin{array}{c}0,00 * * * \\
(0,000)\end{array}$ & $\begin{array}{c}0,00^{* * *} \\
(0,000)\end{array}$ & $\begin{array}{c}0,00 * * * \\
(0,000)\end{array}$ & $\begin{array}{c}0,00 * * * \\
(0,000)\end{array}$ & $\begin{array}{c}0,00 * * * \\
(0,000)\end{array}$ & $\begin{array}{l}0,00 * * \\
(0,010)\end{array}$ & $\begin{array}{c}0,00^{*} \\
(0,054)\end{array}$ & $\begin{array}{c}0,00 * * * \\
(0,000)\end{array}$ \\
\hline $\begin{array}{l}\text { PIB per } \\
\text { cap }\end{array}$ & $\begin{array}{c}-0,00^{* *} \\
(0,010)\end{array}$ & $\begin{array}{c}0,00 \\
(0,282)\end{array}$ & $\begin{array}{c}0,00 \\
(0,908)\end{array}$ & $\begin{array}{c}-0,00 \\
(0,465)\end{array}$ & $\begin{array}{c}-0,00 \\
(0,120)\end{array}$ & $\begin{array}{c}-0,00 * * \\
(0,022)\end{array}$ & $\begin{array}{c}-0,00^{* * *} \\
(0,001)\end{array}$ & $\begin{array}{c}-0,00^{* * *} \\
(0,001)\end{array}$ & $\begin{array}{c}-0,00 * * * \\
(0,000)\end{array}$ & $\begin{array}{c}-0,00 * * \\
(0,045)\end{array}$ & $\begin{array}{c}-0,00^{* * *} \\
(0,007)\end{array}$ \\
\hline Spread & $\begin{array}{l}-0,03 \\
(0,246)\end{array}$ & $\begin{array}{c}-0,07^{\star * *} \\
(0,005)\end{array}$ & $\begin{array}{c}-0,11^{* * *} \\
(0,000)\end{array}$ & $\begin{array}{c}-0,06^{* * *} \\
(0,002)\end{array}$ & $\begin{array}{c}-0,06 \\
(0,120)\end{array}$ & $\begin{array}{l}-0,00 \\
(0,955)\end{array}$ & $\begin{array}{c}-0,00 \\
(0,668)\end{array}$ & $\begin{array}{c}0,02 \\
(0,525)\end{array}$ & $\begin{array}{c}0,02 \\
(0,380)\end{array}$ & $\begin{array}{c}-0,01 \\
(0,790)\end{array}$ & $\begin{array}{c}-0,00 \\
(0,860)\end{array}$ \\
\hline Const & $\begin{array}{c}27,20 * * * \\
(0,000)\end{array}$ & $\begin{array}{c}18,75^{* * *} \\
(0,000)\end{array}$ & $\begin{array}{c}19,80 * * * \\
(0,000)\end{array}$ & $\begin{array}{c}21,25^{* * *} \\
(0,000)\end{array}$ & $\begin{array}{c}22,68^{* * *} \\
(0,000)\end{array}$ & $\begin{array}{c}24,48 * * * \\
(0,000)\end{array}$ & $\begin{array}{c}26,00 * * * \\
(0,000)\end{array}$ & $\begin{array}{c}27,84^{* * *} \\
(0,000)\end{array}$ & $\begin{array}{c}31,14^{\star * *} \\
(0,000)\end{array}$ & $\begin{array}{c}35,37 * * * \\
(0,000)\end{array}$ & $\begin{array}{c}25,12^{* * *} \\
(0,000)\end{array}$ \\
\hline
\end{tabular}

*** Significativo no nível de I\%; *** significativo no nível de 5\%; * significativo no nível de I०\%.

Nota: $p$-value entre parênteses.

Fonte: Elaborada pelos autores.

Observa-se que os coeficientes relativos às variáveis explicativas RegTrab e custo de demitir, para o quantil o,54 representativo do Brasil, são significantes a I\% e 5\%, respectivamente, sugerindo que há relação entre a regulação trabalhista e o investimento interno no Brasil. Um aumento de um ponto na escala de rigidez da regulação trabalhista, levando em consideração a rigidez do contrato de trabalho na contratação, demissão e carga horária, proporciona uma retração de 0,068 no investimento interno em termos de formação bruta de capital fixo no Brasil (percentual sobre o PIB). No mesmo sentido, um aumento da rigidez da regulação trabalhista, tomando como referência o custo por demitir em semana de salários (dólares), implica a redução de ০,०2 do nível de investimento em ativos fixos no país.

Além disso, quando se analisam os testes, verifica-se que, para quase todos os demais quantis, essa relação se confirma, o que permite inferir que a rigidez da regulação trabalhista tem impacto sobre o investimento em termos de formação 
bruta de capital fixo (\% PIB) para maioria dos países da amostra. Isso revela que, em geral, uma redução da rigidez na regulação do trabalho pode promover uma expansão do volume de investimento em ativos fixos nos países.

Pelo método MQO, também se verifica a relação entre essas variáveis, sendo os coeficientes significantes a I\% para RegTrab e Io\% para custo de demitir, conforme a Tabela 6 . Contudo, ressalta-se que, se a análise fosse baseada no método MQO, uma análise particular do Brasil não seria possível, pois teríamos um só valor médio para toda amostra representativa dos países, de tal modo que não seria possível avaliar se o Brasil se encontrava próximo ou longe dessa média.

A relação entre regulação trabalhista e investimento interno, conforme indica a literatura, pode ser explicada pelo fato de a redução da rigidez da regulação trabalhista conferir maior liberdade de negociação na relação de trabalho entre empregador e empregado e desonerar os custos ligados à mão de obra, criando oportunidades para investimentos em aquisições de ativos fixos responsáveis pela composição da formação bruta de capital fixo, sem que isso implique necessariamente efeitos desfavoráveis sobre o emprego. Isso porque estudos anteriores demonstraram que legislações trabalhistas muito rígidas e pró-trabalhadores têm efeitos adversos sobre o emprego, a produtividade e o crescimento das empresas, entre outros (DOING BUSINESS, 2009).

Quanto ao efeito da regulação trabalhista no investimento externo, a Tabela 7 mostra as estimativas obtidas pela regressão quantílica (RQ) para os quantis 0,I, ०,2, ०,3, ०,4, 0,5, ०,6, ०,7, ०,8, ०,9 e ०,39 (Brasil). A variável dependente é o investimento externo (fluxo de entrada de investimento estrangeiro direto), e a independente, a regulação trabalhista (RegTrab e custo de demitir).

Os resultados demonstram que há relação entre a regulação trabalhista e o investimento estrangeiro direto no Brasil, uma vez que os coeficientes referentes à RegTrab e custo de demitir são estatisticamente significativos a 5\% e I०\%, respectivamente, um aumento de um ponto na escala de rigidez do contrato de trabalho, considerando processos de contratação, demissão e carga horária, pode elevar o fluxo de entrada de investimento estrangeiro direto (percentual do PIB) em 0,02 , enquanto uma redução do custo de demitir em semanas de salários pode elevar o nível de investimento externo atraído para o Brasil em o,००7, como exposto na Tabela 7 . 


\section{TABELA 7}

\section{RESULTADOS POR RQ E MQO. EFEITO DA REGULAÇÃO TRABALHISTA NO INVESTIMENTO EXTERNO}

\begin{tabular}{|c|c|c|c|c|c|c|c|c|c|c|c|}
\hline VARIÁVEL & MQO & $\mathrm{RQ} 0,1$ & $\mathrm{RQ} 0,2$ & $\mathrm{RQ} 0,3$ & $\mathrm{RQ} 0,4$ & $\mathrm{RQ} 0,5$ & $\mathrm{RQ} 0,6$ & $\mathrm{RQ} 0,7$ & $\mathrm{RQ} 0,8$ & $\mathrm{RQ} 0,9$ & $\begin{array}{c}R Q \\
0,39 \text { (BRASIL) }\end{array}$ \\
\hline RegTrab & $\begin{array}{c}-0,02 \\
(0,205)\end{array}$ & $\begin{array}{c}0,00 \\
(0,455)\end{array}$ & $\begin{array}{c}0,00 \\
(0,275)\end{array}$ & $\begin{array}{l}-0,00 \\
(0,644)\end{array}$ & $\begin{array}{l}-0,02^{* *} \\
(0,044)\end{array}$ & $\begin{array}{c}-0,02^{\star *} \\
(0,033)\end{array}$ & $\begin{array}{c}-0,03^{* *} \\
(0,042)\end{array}$ & $\begin{array}{l}-0,04^{* *} \\
(0,041)\end{array}$ & $\begin{array}{l}-0,06^{*} \\
(0,088)\end{array}$ & $\begin{array}{c}-0,05 \\
(0,408)\end{array}$ & $\begin{array}{c}-0,020 * * \\
(0,033)\end{array}$ \\
\hline Custo de demitir & $\begin{array}{c}0,00 \\
(0,973)\end{array}$ & $\begin{array}{c}0,00 \\
(0,979)\end{array}$ & $\begin{array}{c}-0,00 \\
(0,492)\end{array}$ & $\begin{array}{c}-0,00 \\
(0,468)\end{array}$ & $\begin{array}{c}-0,00 \\
(0,107)\end{array}$ & $\begin{array}{l}-0,00^{*} \\
(0,088)\end{array}$ & $\begin{array}{l}-0,00 \\
(0,264)\end{array}$ & $\begin{array}{c}-0,01 \\
(0,103)\end{array}$ & $\begin{array}{l}-0,02^{*} \\
(0,060)\end{array}$ & $\begin{array}{c}-0,02 \\
(0,224)\end{array}$ & $\begin{array}{r}-0,007^{\star} \\
(0,065)\end{array}$ \\
\hline PopTotal & $\begin{array}{c}-0,00^{* *} \\
(0,049)\end{array}$ & $\begin{array}{c}0,00^{* * *} \\
(0,000)\end{array}$ & $\begin{array}{l}0,00 * * \\
(0,020)\end{array}$ & $\begin{array}{c}0,00 \\
(0,519)\end{array}$ & $\begin{array}{c}-0,00 \\
(0,838)\end{array}$ & $\begin{array}{c}-0,00 \\
(0,251)\end{array}$ & $\begin{array}{c}-0,00 \\
(0,503)\end{array}$ & $\begin{array}{c}-0,00 \\
(0,478)\end{array}$ & $\begin{array}{c}-0,00 \\
(0,566)\end{array}$ & $\begin{array}{c}-0,00 \\
(0,632)\end{array}$ & $\begin{array}{l}-0,00 \\
(0,843)\end{array}$ \\
\hline PIB per cap & $\begin{array}{c}-0,00 \\
(0,529)\end{array}$ & $\begin{array}{c}-0,00 \\
(0,326)\end{array}$ & $\begin{array}{c}-0,00 \\
(0,544)\end{array}$ & $\begin{array}{c}-0,00 \\
(0,513)\end{array}$ & $\begin{array}{l}-0,00^{*} \\
(0,073)\end{array}$ & $\begin{array}{c}-0,00 \\
(0,106)\end{array}$ & $\begin{array}{l}-0,00 \\
(0,320)\end{array}$ & $\begin{array}{c}-0,00 \\
(0,726)\end{array}$ & $\begin{array}{c}0,00 \\
(0,803)\end{array}$ & $\begin{array}{l}0,00 * * \\
(0,022)\end{array}$ & $\begin{array}{c}-0,00 \text { ** } \\
(0,030)\end{array}$ \\
\hline Spread & $\begin{array}{c}-0,00 \\
(0,766)\end{array}$ & $\begin{array}{c}-0,00 \\
(0,446)\end{array}$ & $\begin{array}{c}-0,01 \\
(0,173)\end{array}$ & $\begin{array}{c}-0,01 \\
(0,515)\end{array}$ & $\begin{array}{c}-0,00 \\
(0,658)\end{array}$ & $\begin{array}{c}-0,00 \\
(0,621)\end{array}$ & $\begin{array}{c}-0,01 \\
(0,520)\end{array}$ & $\begin{array}{c}0,00 \\
(0,789)\end{array}$ & $\begin{array}{c}0,02 \\
(0,624)\end{array}$ & $\begin{array}{c}0,19 * * * \\
(0,001)\end{array}$ & $\begin{array}{c}-0,00 \\
(0,680)\end{array}$ \\
\hline Const & $\begin{array}{c}6,32 * * * \\
(0,000)\end{array}$ & $\begin{array}{c}0,16 \\
(0,535)\end{array}$ & $\begin{array}{c}0,65 \\
(0,107)\end{array}$ & $\begin{array}{c}2,07^{* * *} \\
(0,003)\end{array}$ & $\begin{array}{c}3,83^{* * *} \\
(0,000)\end{array}$ & $\begin{array}{c}4,87^{* * *} \\
(0,000)\end{array}$ & $\begin{array}{c}6,52^{* * *} \\
(0,000)\end{array}$ & $\begin{array}{c}7,78^{* * *} \\
(0,000)\end{array}$ & $\begin{array}{c}11,31^{* * *} \\
(0,000)\end{array}$ & $\begin{array}{c}10,98^{* * *} \\
(0,000)\end{array}$ & $\begin{array}{c}3,795^{* * *} \\
(0,000)\end{array}$ \\
\hline
\end{tabular}

**** Significativo no nível de I\%; ** significativo no nível de 5\%; * significativo no nível de ı०\%.

Nota: $p$-value entre parênteses.

Fonte: Elaborada pelos autores.

Assim sendo, os resultados evidenciam que a atração de níveis mais altos de investimentos estrangeiros diretos está relacionada à redução da rigidez da regulação trabalhista no Brasil e nos demais países, como os representados pelos quantis 0,3 (Estados Unidos), o,4 (Venezuela), 0,5 (Argentina, França), o,6, 0,7 (Uruguai) e o,8 (Chile).

De fato, estudos anteriores demonstraram que a maior flexibilidade no mercado de trabalho do país que recebe o investimento implica maior probabilidade de investimento e maiores fluxos de investimento estrangeiro direto, tendo em vista que os custos com mão de obra compõem parte substancial dos custos totais de um empreendimento.

Para fins de comparação, destaca-se que pelo método MQO não houve significância estatística, ou seja, por meio do MQO não seria possível verificar o efeito da regulação trabalhista no investimento externo no Brasil. Percebe-se que a regressão quantílica consegue capturar os efeitos de porções da amostra, permitindo uma análise individualizada. 


\subsubsection{Regulação tributária}

Em relação ao efeito da regulação tributária no investimento interno, a Tabela 8 mostra as estimativas obtidas pela regressão quantílica (RQ) para os quantis

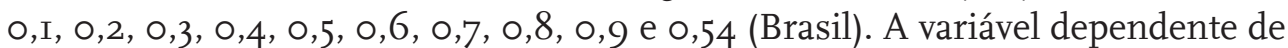
interesse é o investimento interno (formação bruta de capital fixo), e a independente, a regulação tributária (imposto de renda corporativo total).

De acordo com as estimativas, há relação entre a regulação tributária e o investimento interno no Brasil, uma vez que o coeficiente da variável imposto total incidente sobre o lucro empresarial é significante a $5 \%$. Os resultados sugerem que um aumento da carga tributária medida pelo percentual de tributação sobre o lucro pode gerar uma retração de 0,02 do volume de investimentos das empresas em ativos fixos no Brasil (percentual sobre o PIB).

\section{TABELA 8}

\section{RESULTADOS POR RQ E MQO.EFEITO DA REGULAÇÃO} TRIBUTÁRIA NO INVESTIMENTO INTERNO

Variável dependente: investimento interno (formação bruta de capital fixo).

Variável independente: regulação tributária (número de pagamentos por ano; tempo; imposto de renda corporativo total).

\begin{tabular}{|c|c|c|c|c|c|c|c|c|c|c|c|}
\hline VARIÁVEL & MQO & $\mathrm{RQ} 0,1$ & $\mathrm{RQ} 0,2$ & $\mathrm{RQ} 0,3$ & $\mathrm{RQ} 0,4$ & $\mathrm{RQ} 0,5$ & $\mathrm{RQ} 0,6$ & RQ 0,7 & RQ 0,8 & RQ 0,9 & $\begin{array}{c}\text { RQ } \\
0,54 \text { (BRASIL) }\end{array}$ \\
\hline $\begin{array}{l}\text { Imposto } \\
\text { renda corp }\end{array}$ & $\begin{array}{c}-0,02 * * \\
(0,026)\end{array}$ & $\begin{array}{c}-0,03^{* * *} \\
(0,000)\end{array}$ & $\begin{array}{c}-0,03^{* * *} \\
(0,000)\end{array}$ & $\begin{array}{l}-0,01 * \\
(0,071)\end{array}$ & $\begin{array}{c}-0,01 \\
(0,167)\end{array}$ & $\begin{array}{l}-0,02^{*} \\
(0,099)\end{array}$ & $\begin{array}{c}-0,02^{* \star *} \\
(0,002)\end{array}$ & $\begin{array}{c}-0,03^{* * *} \\
(0,003)\end{array}$ & $\begin{array}{c}-0,04^{\star * *} \\
(0,000)\end{array}$ & $\begin{array}{c}-0,03^{* *} \\
(0,021)\end{array}$ & $\begin{array}{l}-0,02^{* *} \\
(0,016)\end{array}$ \\
\hline Poptotal & $\begin{array}{c}0,00^{* * *} \\
(0,002)\end{array}$ & $\begin{array}{c}0,00^{* * *} \\
(0,000)\end{array}$ & $\begin{array}{c}0,00 * * * \\
(0,000)\end{array}$ & $\begin{array}{c}0,00^{* * *} \\
(0,000)\end{array}$ & $\begin{array}{c}0,00 * * * \\
(0,000)\end{array}$ & $\begin{array}{c}0,00 * * * \\
(0,005)\end{array}$ & $\begin{array}{c}0,00 * * * \\
(0,010)\end{array}$ & $\begin{array}{c}0,00^{* * *} \\
(0,000)\end{array}$ & $\begin{array}{c}0,00 * * * \\
(0,003)\end{array}$ & $\begin{array}{c}0,00^{* * *} \\
(0,000)\end{array}$ & $\begin{array}{c}0,00^{* * *} \\
(0,002)\end{array}$ \\
\hline PIB per cap & $\begin{array}{c}-0,00 \\
(0,168)\end{array}$ & $\begin{array}{c}0,00 \\
(0,352)\end{array}$ & $\begin{array}{c}0,00 \\
(0,969)\end{array}$ & $\begin{array}{c}-0,00 \\
(0,970)\end{array}$ & $\begin{array}{c}-0,00 \\
(0,649)\end{array}$ & $\begin{array}{c}-0,00 \\
(0,203)\end{array}$ & $\begin{array}{c}-0,00^{* * *} \\
(0,009)\end{array}$ & $\begin{array}{c}-0,00^{* *} \\
(0,014)\end{array}$ & $\begin{array}{c}-0,00^{\star * *} \\
(0,000)\end{array}$ & $\begin{array}{l}-0,00^{*} \\
(0,077)\end{array}$ & $\begin{array}{l}-0,00^{*} \\
(0,054)\end{array}$ \\
\hline Const & $\begin{array}{c}24,18 \\
(0,000)\end{array}$ & $\begin{array}{c}16,90 \\
(0,000)\end{array}$ & $\begin{array}{c}18,88 \\
(0,000)\end{array}$ & $\begin{array}{c}19,46 \\
(0,000)\end{array}$ & $\begin{array}{c}20,85 \\
(0,000)\end{array}$ & $\begin{array}{c}22,70 \\
(0,000))\end{array}$ & $\begin{array}{c}24,67 \\
(0,000)\end{array}$ & $\begin{array}{c}27,17 \\
(0,000)\end{array}$ & $\begin{array}{c}30,57 \\
(0,000)\end{array}$ & $\begin{array}{c}33,67 \\
(0,000)\end{array}$ & $\begin{array}{c}23,38 \\
(0,000)\end{array}$ \\
\hline
\end{tabular}

*** Significativo no nível de I\%; ** significativo no nível de 5\%; * significativo no nível de I0\%.

Nota: $p$-value entre parênteses.

Fonte: Elaborada pelos autores.

No que tange ao efeito da regulação tributária no investimento externo no Brasil, conforme resultados expostos na Tabela 9, há relação entre a regulação tributária e o investimento externo no Brasil, pois o coeficiente da variável imposto total sobre o lucro é significativo em ı०\%. Pelo método dos mínimos 
quadrados ordinários, não houve significância do coeficiente da variável explicativa da regulação tributária. Dessa forma, caso fosse utilizado esse método para realização dos testes, não seria possível visualizar a relação entre regulação tributária e investimento externo no Brasil.

A Tabela 9 mostra que uma redução na tributação sobre o lucro pode levar a um aumento de o,or no fluxo de entrada de investimento estrangeiro direto no Brasil (\% PIB).

Vale salientar que a relação entre a tributação total sobre o lucro empresarial e o investimento externo ocorre apenas para países representados pelo quantil o,3, como os Estados Unidos, além do quantil o,39 representativo do Brasil. Segundo dados do Doing Business (2009), os Estados Unidos registram um índice de tributação sobre o lucro (\%) de 27,9, enquanto o do Brasil é de 2I,3, valores acima do índice médio de i8,I2 dos países da amostra ${ }^{6}$. Isso evidencia um montante de impostos incidente sobre o lucro das empresas superior à média dos países. Nesse sentido, uma redução da carga de tributo incidente sobre o lucro empresarial nesses países pode ter maior efeito sobre a atração de investimentos estrangeiros diretos.

\section{TABELA 9}

\section{RESULTADOS POR RQ E MQO. EFEITO DA REGULAÇÃO TRIBUTÁRIA NO INVESTIMENTO EXTERNO}

Variável dependente: investimento externo (fluxo de entrada de investimento estrangeiro direto). Variável independente: regulação tributária (número de pagamentos por ano; tempo; imposto de renda corporativo total).

\begin{tabular}{|c|c|c|c|c|c|c|c|c|c|c|c|}
\hline VARIÁVEL & MQO & $\mathrm{RQ} 0,1$ & $\mathrm{RQ} 0,2$ & $\mathrm{RQ} 0,3$ & $\mathrm{RQ} 0,4$ & $\mathrm{RQ} 0,5$ & RQ 0,6 & RQ 0,7 & $\mathrm{RQ} 0,8$ & RQ 0,9 & $\begin{array}{c}\text { RQ } \\
0,39 \text { (BRASIL) }\end{array}$ \\
\hline $\begin{array}{l}\text { Imposto } \\
\text { total sobre lucro }\end{array}$ & $\begin{array}{c}-0,00 \\
(0,822)\end{array}$ & $\begin{array}{c}-0,00 \\
(0,489)\end{array}$ & $\begin{array}{c}-0,00 \\
(0,318)\end{array}$ & $\begin{array}{c}-0,00 * * * \\
(0,010)\end{array}$ & $\begin{array}{c}-0,01 \\
(0,128)\end{array}$ & $\begin{array}{c}-0,00 \\
(0,167)\end{array}$ & $\begin{array}{c}-0,00 \\
(0,913)\end{array}$ & $\begin{array}{c}0,00 \\
(0,805)\end{array}$ & $\begin{array}{c}0,00 \\
(0,939)\end{array}$ & $\begin{array}{c}0,01 \\
(0,960)\end{array}$ & $\begin{array}{l}-0,01^{*} \\
(0,080)\end{array}$ \\
\hline Poptotal & $\begin{array}{c}-0,00 \\
(0,462)\end{array}$ & $\begin{array}{c}0,00 \\
(0,125)\end{array}$ & $\begin{array}{c}0,00 \\
(0,781)\end{array}$ & $\begin{array}{c}-0,00 \\
(0,877)\end{array}$ & $\begin{array}{c}-0,00 \\
(0,317)\end{array}$ & $\begin{array}{c}-0,00 \\
(0,250)\end{array}$ & $\begin{array}{c}-0,00 \\
(0,423)\end{array}$ & $\begin{array}{c}-0,00 \\
(0,318)\end{array}$ & $\begin{array}{c}-0,00 \\
(0,612)\end{array}$ & $\begin{array}{l}-0,00 * \\
(0,060)\end{array}$ & $\begin{array}{c}-0,00 \\
(0,345)\end{array}$ \\
\hline PIB per cap & $\begin{array}{c}0,00 * * * \\
(0,00)\end{array}$ & $\begin{array}{c}-0,00 \\
(0,172)\end{array}$ & $\begin{array}{c}0,00 \\
(0,849)\end{array}$ & $\begin{array}{c}-0,00 \\
(0,371)\end{array}$ & $\begin{array}{c}-0,00 \\
(0,743)\end{array}$ & $\begin{array}{c}0,00 \\
(0,923)\end{array}$ & $\begin{array}{c}0,00 * \\
(0,082)\end{array}$ & $\begin{array}{l}0,00 * * * \\
(0,001)\end{array}$ & $\begin{array}{l}0,00 * * * \\
(0,000)\end{array}$ & $\begin{array}{l}0,00 * * * \\
(0,004)\end{array}$ & $\begin{array}{c}-0,00 \\
(0,772)\end{array}$ \\
\hline Const & $\begin{array}{c}1,90 \\
(0,432)\end{array}$ & $\begin{array}{l}0,44 * * \\
(0,029)\end{array}$ & $\begin{array}{l}1,22 * * * \\
(0,000)\end{array}$ & $\begin{array}{l}2,16 * * * \\
(0,000)\end{array}$ & $\begin{array}{l}3,21 * * * \\
(0,000)\end{array}$ & $\begin{array}{l}3,83 * * * \\
(0,000)\end{array}$ & $\begin{array}{l}4,31 * * * \\
(0,000)\end{array}$ & $\begin{array}{l}5,28 * * * \\
(0,000)\end{array}$ & $\begin{array}{l}6,36 * * * \\
(0,000)\end{array}$ & $\begin{array}{c}10,69 * * * \\
(0,000)\end{array}$ & $\begin{array}{l}3,20 * * * \\
(0,000)\end{array}$ \\
\hline
\end{tabular}

*** Significativo no nível de I\%; ** significativo no nível de 5\%; * significativo no nível de I०\%. Nota: p-value entre parênteses.

Fonte: Elaborada pelos autores. 
Assim, os resultados do presente estudo sugerem que a carga tributária pode ser uma das determinantes para atração de investimento estrangeiro no Brasil. De forma similar, resultados de estudos anteriores encontraram que a carga tributária de um país é uma determinante na tomada de decisão de investimento, afetando o volume e a localização do fluxo de investimento estrangeiro direto. Uma alta carga de tributos reduz o retorno pós-tributação, inibindo assim os incentivos para investimentos (HINES, 2005).

\section{CONSIDERAÇÕES FINAIS}

O objetivo deste estudo foi investigar o efeito da regulação trabalhista e tributária nos investimentos internos e externos no Brasil, fornecendo evidências empíricas dos efeitos dessas legislações sobre os investimentos e as estratégias de negócios no Brasil.

O estudo contribui para a literatura ao fornecer uma análise empírica focada no Brasil, a partir de uma análise cross-country com dados em pooled cross-section utilizando regressão quantílica, tendo em vista que a maior parte dos estudos existentes concentra a análise em outras relações, com foco em outros países, utilizando diferentes amostras, variáveis e técnicas estatísticas.

Os resultados encontrados para o efeito da regulação trabalhista sobre os investimentos estão de acordo com as teorias apresentadas e refletem que a maior rigidez da regulação do trabalho impõe níveis menores de investimentos no Brasil, em termos de formação bruta de capital fixo e investimento estrangeiro direto.

Percebe-se que uma redução da rigidez da regulação trabalhista pode elevar os investimentos no Brasil. Ao contrário, uma alta rigidez da regulação trabalhista pode não apenas inibir os investimentos e o desempenho econômico, como também pode ser ineficiente na garantia do emprego - objetivo maior da tutela da lei.

A análise dos resultados dos testes relacionados ao efeito da regulação tributária no investimento interno demonstrou significância estatística, ou seja, foi encontrada relação entre a carga de tributos incidentes sobre as empresas - considerando a tributação total sobre o lucro empresarial - e os níveis de investimentos, tomando como medida os índices de formação bruta de capital fixo e o fluxo de entrada de investimento estrangeiro direto (ambos em percentual sobre o PIB). Esses resultados encontram suporte na literatura, já que evidências empíricas anteriores sugerem que elevada carga tributária reduz o retorno póstributação, inibindo, assim, os incentivos para investimentos. 


\section{THE IMPACT OF LABOR AND TAX REGULATIONS ON INVESTMENTS IN BRAZIL}

\section{ABSTRACT}

This study aims to assess the impact of the labor and tax regulations on the internal (gross formation of fixed capital) and external investment (direct foreign investment inward flow). Therefore, empirical evidences for the impacts of the labor and tax legislation on the investments and business strategies in Brazil were collected. Studies in this field are justified by the relevant effect of the regulation on the agents economic activities, since, despite the economic, social, and political reasons are used to justify the regulation, an empirical evidence is seldom applied as a basis or justification for the regulation (ALMEIDA; CARNEI$\mathrm{RO}, 2005)$. Focusing on Brazil is significant as it is one of the world's most regulated countries in the labor and tax scope, with low enforcement (BOTERO et al., 2004), the strictness of such legislations may interfere in the companies' poor performance and investments as well as in the country's economic growth. In order to investigate the labor and tax regulation impact on the national and international investments, tests were applied under the Quantile Regression (QR) method. For comparative analysis purposes, the tests were also made under the Ordinary Least Squares (OLS) method. This is a cross-country study based on pooled cross-section data from I80 countries, gathered from 2003 to 2006 concerning the labor regulation and within the period from 2005 to 2006 concerning the tax regulation. The data with regard to the variables and the national and international investments (dependant variables), as well as the GDP, total inhabitants, and interests rate (control variables), are provided by the World Development Indicators updated in 2008 . The results found suggest that the higher the labor regulation strictness, the lower the investment level regarding gross formation of fixed capital and direct foreign investment in Brazil. With regard to the effect of the tax regulation on investments, the results demonstrate that they are statistically relevant and that a reduction in the tax load, measured by the taxation over the business profit, could raise the investment level.

\section{KEYWORDS}

Labor and tax regulation; Investments in Brazil; World Bank; GDP; Economic performance. 


\section{EL EFECTO DE LA REGULACIÓN LABORAL Y TRIBUTARIA EN LAS INVERSIONES EN BRASIL}

\section{RESUMEN}

El objetivo de este estudio es evaluar el efecto de la regulación laboral y tributaria en la inversión interna (formación bruta de capital fijo) y externo (flujo de entrada de inversión extranjera directa). Así, se buscó suministrar evidencias empíricas de los efectos de la legislación laboral y tributaria sobre las inversiones y estrategias de negocios en Brasil. Estudios en este campo se justifican por el hecho de que la regulación tiene impacto sustancial en la actividad económica de los agentes, porque a pesar de que se usen razones económicas, sociales y políticas para justificar la regulación, raramente se utiliza alguna evidencia empírica como base o justificación para regulación (ALMEIDA; CARNEIRO, 2005). El foco en Brasil es relevante por ser uno de los países más regulados del mundo en el ámbito laboral y tributario, presentando bajo enforcement (BOTERO et al., 2004), y la rigidez de esas legislaciones puede ser un factor de interferencia en el bajo desempeño y inversiones de las empresas y en el crecimiento económico del país. Para investigar el efecto de la regulación laboral y tributaria en la inversión interna y externa se aplicaron pruebas por medio del método de regresión cuantílica (RQ). Para efecto de análisis comparativo, también se rodó las pruebas por el método de los mínimos cuadrados ordinarios (MQO). El estudio es cross-country basado en datos en pooled crosssection de I80 países, recogidos en el período de 2003 a 2006 para regulación laboral y en el período de 2005 a 2006. Los datos relativos a las variables e inversiones interna y externa (variables dependientes), así como del PIB, población total y tasa de intereses (variables de control) son provenientes del World Development Indicators actualizado en el año 2008. Los resultados encontrados sugieren que cuanto mayor es la rigidez de la regulación del trabajo, menor es el nivel de inversión en términos de formación bruta de capital fijo y inversión extranjera directa en Brasil. En cuanto al efecto de la regulación tributaria sobre las inversiones, los resultados demuestran que hay significación estadística y que una reducción de la carga tributaria, medida (152) por la tributación sobre las ganancias empresariales, puede elevar los niveles de inversiones.

\section{PALABRAS CLAVE}

Regulación laboral y tributaria; Inversiones en Brasil; Banco Mundial; PIB; Desempeño económico. 


\section{REFERÊNCIAS}

ALMEIDA, R.; CARNEIRO, P. Enforcement of regulation, informal labor and firm performance. Policy Research Working Paper. World Bank WPS3756. Jan. 2005. Disponível em: <http://econ. worldbank.org/external/default/main?pagePK=64I65259\&theSitePK=469372\&piPK=64I6542I\& menuPK=64I66093\&entityID=0000I6406_2005I0I7I73I27>. Acesso em: 4 abr. 2009.

AMARAL, G. L. et al. Carga tributária brasileira 2008. IBPT, Curitiba, v. I, mar. 2009. Disponível em: <http://www.ibpt.com.br/>. Acesso em: maio 2009.

BESLEY, T. J.; BURGESS, R. Can labour regulation hinder economic performance? Evidence from India. MIT Press Journals, Massachusetts, v. II9, n. I, p. 9I-I34, Feb. 2002. Disponível em: <http:// www.mitpressjournals.org/doi/abs/ıo.II62/003355304772839533>. Acesso em: 2 maio 2009.

BOTERO, J. et al. The regulation of labor. Quarterly Journal of Economics, Cambridge, v. II9, n. 4, p. I339-1382, June 2004. Disponível em: <http://www.doingbusiness.org/documents/labor_Juneo4. pdf $>$. Acesso em: 2 maio 2009 .

COOTER, R.; ULEN, T. Law \& Economics. 4. ed. Pearson Education, 2004.

DAVIS, S. J.; HENREKSON, M. Tax effects on work activity, industry mix and shadow economy size: evidence from rich-country comparisons. National Bureau of Economic Research, Cambridge, v. 2, Sept. 2004. Disponível em: <http://www.nber.org/>. Acesso em: abr. 2009.

DESAI, M.; HINES, J.; FOLEY, F. Foreign direct investment in a world on multiple taxes. Working paper 8440. Cambridge: National Bureau of Economic Research, 200I.

DJANKOV, S. et al. The new comparative economics. Journal of Comparative Economics, Cambridge, v. 3I, n. 9.608, p. 595-619, Apr. 2003.

The effect of corporate taxes on investment and entrepreneurship. NBER Working Paper

Series, v. wi3756. Cambridge: The National Bureau of Economic Research, 2008.

DOING BUSINESS - Banco Mundial. Disponível em: <http://www.doingbusines.org>. Acesso em: mar. 2009 .

GLAESER, E.; SCHEINKMAN, E.; SHLEIFER, A. The injustice of inequality. Harvard Institute Research Working Paper, Cambridge, v. 50, n. I967, p. 199-222, Jan. 2002. Disponível em: <http:// ssrn.com/abstract=32126I >. Acesso em: abr. 2009.

HALLOCK, K. F.; KOENKER, R. Quantile regression: an introduction. Journal of Economic Perspectives, Illinois, v. I5, n. 4, p. I43-I56, Oct. 2000.

HINES, J. Corporate taxation and international competition. 2005. Disponível em: <www.bus. umich.edu/otpr/wp2005-9.pdf>. Acesso em: maio 2009.

INSTITUTO BRASILEIRO DE GEOGRAFIA E ESTATÍSTICA - IBGE. Disponível em: <http:// www.ibge.gov.br>. Acesso em: mar. 2009 .

INSTITUTO DE PESQUISA ECONÔMICA APLICADA - IPEA. Ipeadata. Disponível em: <http:// www.ipeadata.gov.br>. Acesso em: mar. 2009.

JAVORCIK, B. S.; SPATAREANU, M. Do foreign investors care about labor market regulations? Review of World Economics, Springer, v. I4I, n. 3, p. 375-403, Oct. 2006. Disponível em: <http:// ideas.repec.org>. Acesso em: abr. 2009.

LAZEAR, E. P. Job security provisions and employment. The Quarterly Journal of Economics, Cambridge, v. I05, n. 3, p. 699-726, Aug. I990. 
ORGANISATION FOR ECONOMIC CO-OPERATION AND DEVELOPMENT - OECD. Disponível em: <http://www.oecd.org>. Acesso em: mar. 2009.

PIERRE, G.; SCARPETTA, S. Employment regulations through the eyes of employers. Do they matter and how do firms respond to them? World Bank Policy Research Paper n. 3463. 2005. Disponível em: <http://ssrn.com/abstract=64322I>. Acesso em: mar. 2009.

POSNER, R. A. Economic analysis of law. Chicago: Wolters Kluwer, 2003.

UNITED NATIONS CONFERENCE ON TRADE AND DEVELOPMENT - UNCTAD. Disponível em: <http://www.unctad.org>. Acesso em: mar. 2009.

WORLD DEVELOPMENT INDICATORS - WDI. 2008. Disponível em: <http://data.worldbank. org/indicator>. Acesso em: set. 2009.

WORLD INVESTMENT REPORT DIVISION ON INVESTMENT AND ENTERPRISE. Disponível em: <http://www.unctad.org>. Acesso em: abr. 2009. 